\title{
Water-Assisted Transamination of Glycine and Formaldehyde
}

\author{
Rong-Zhen Liao, Wan-Jian Ding, Jian-Guo Yu,* Wei-Hai Fang, and Ruo-Zhuang Liu* \\ College of Chemistry, Beijing Normal University, Beijing 100875, People's Republic of China
}

Received: January 7, 2007; In Final Form: February 26, 2007

\begin{abstract}
A computational study on the transamination reaction of molecular complexes that consist of $\mathrm{NH}_{2} \mathrm{CH}_{2} \mathrm{COOH}$ $+\mathrm{CH}_{2} \mathrm{O}+n \mathrm{H}_{2} \mathrm{O}$, where $n=0,1,2$, is presented. This work has allowed the description of the geometries of all the intermediates and transition states of the reactions, which can be described by five steps: carbinolamine formation, dehydration, 1,3 proton transfer, hydrolysis, and carbinolamine elimination. Among the five steps of the reaction, hydrolysis and elimination occur with the existence of general acid catalysis related to the carboxylic group. The water molecules can be involved in the reaction by performing as a proton-transfer carrier and a stabilizing zwitterion. It can be predicted from our calculations that in the transamination between $\alpha$-amino acids and $\alpha$-keto acids, the carbinolamine is formed with small barrier or even barrierless while the dehydration occurs easily at room temperature. However, without heating the 1,3 proton transfer could not occur as the barrier is $26.7 \mathrm{kcal} / \mathrm{mol}$ relative to the reactant complex when including two water molecules. Our results are in good agreement with experimental conclusions.
\end{abstract}

\section{Introduction}

Transamination reactions have been of practical importance and fundamental interest in the metabolism of nitrogencontaining compounds, which are usually considered to be reactions that involve transfer of an amino-group from one molecule to another without the production of free ammonia as an intermediate. ${ }^{1}$ Furthermore, it is one of the most crucial processes in the formation of L-amino acids, in which the L-transaminases catalyzed the conversion of $\alpha$-keto acids to L-amino acids but not D-amino acids. ${ }^{2}$ Direct transamination, uncatalyzed by enzyme, was observed between amino acids and $\alpha$-keto acids, and the mechanism of the reaction could be formulated as follows. ${ }^{3}$

In the reaction, the formed cabinolamine intermediate loses one water molecule to produce an imine (imine 1 in Scheme 1), following an isomerization (transferring a proton to become imine 2), which on hydrolysis yields new $\alpha$-keto acid and amino acid. The key step of the reaction is the proton transfer as it determines the chirality of the generated amino acid ${ }^{2}$ and also it is the rate-limiting step of the whole reaction. ${ }^{4}$ However, without the participation of the enzyme, both L- and D-amino acids could be generated. Furthermore, the effect of substituents on the feasibility of biomimetic isomerization has been studied experimentally, and it was found that the reaction rate strongly depends on both the $\mathrm{CH}$ acidity and steric availability of the transferring proton. ${ }^{5}$

Quantum mechanics calculations have been focused on the carbinolamine formation and elimination involved in the transamination. Theoretical studies investigating ammonia or amine addition to the carbonyl group indicated a decrease of activation barrier when associated with additional water or ammonia molecules. ${ }^{6}$ The effect of some different substituents on the nitrogen and carbon atoms on the addition barrier was found to be minor with the exception of a difluorinated amine. ${ }^{7}$ The subsequent elimination of carbinolamine has also been calculated

* To whom correspondence should be addressed. Phone: (+86)-10-58802051. E-mail: jianguo_yu@bnu.edu.cn.

\section{SCHEME 1}

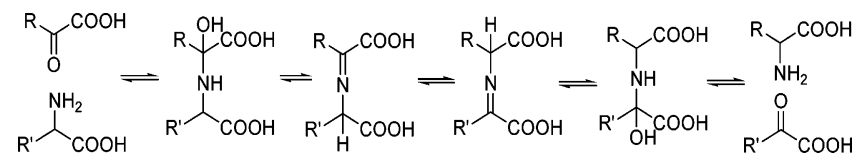

at various levels of theory. ${ }^{6 f, h, i, 8}$ In addition, Salvà et al. ${ }^{9}$ have performed theoretical calculations on the imine formation of 4-pyridinaldehyde and methylamine. They suggested the purpose of including one water molecule in the model reaction was as a reactive species for the reaction to avoid the lack of potential barrier when just the methylamine approached the carbonyl carbon. All these results show that the rate-limiting step of the imine formation is elimination, which is consistent with the experimental results. ${ }^{10}$ However, as far as we know, very little theoretical information is available for the 1,3 proton-transfer step that plays a key role in the whole reaction, especially in the determination of the chirality of amino acids in enzymatic transaminations.

Direct transamination is known to be a symmetrical reaction; therefore, we choose a formaldehyde molecule instead of an amino acid to study the effect of the carboxylic group in the transamination. In this paper, the reference reaction of enzymatic transamination of glycine and formaldehyde as a simple model will be discussed by both ab inito and DFT calculations. As water is the solvent of biological reactions in an organism, which can influence the reaction barrier ${ }^{11}$ by electrostatic stabilization of ionic transition structures, formation of a strong hydrogen bond, and acting as a proton-transfer carrier, it is of immense importance to investigate the influence of the water solvent medium, so the effects of one water molecule and two water molecules on this model transamination are considered.

\section{Computational Details}

Theoretical calculations presented here were carried out with the Gaussian03 program package. ${ }^{12}$ The geometries of reactants, products, intermediates, and transition states involved in this reaction have been fully optimized at the $\mathrm{B} 3 \mathrm{LYP}^{13}$ level of 


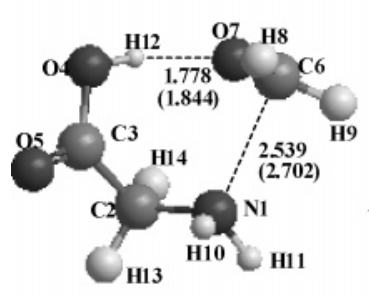

GF1-1

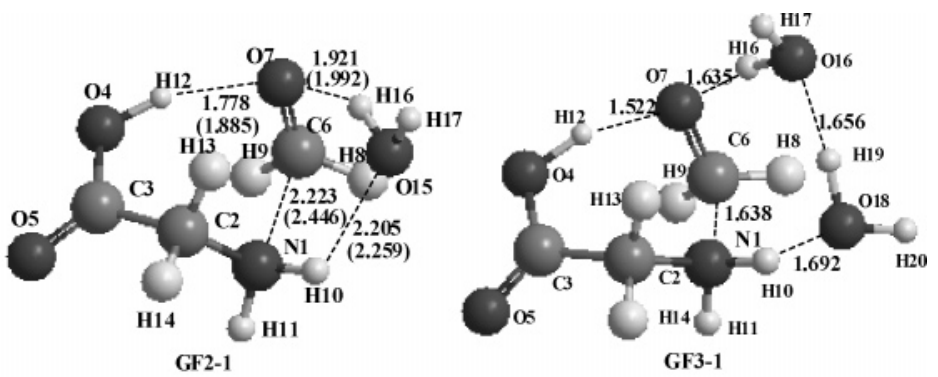

Figure 1. Optimized (B3LYP/6-31G(d,p)) geometries of the starting reactant complexes GF1-1, GF2-1, GF3-1. The MP2/6-31G(d,p) values are in parentheses. The distances are given in angstroms.

theory. The 6-31G(d,p) basis set was used in this study as polarized functions on the hydrogen atoms could provide more accurate descriptions for the hydrogen transfer reactions and hydrogen-bonded species of this study. The IRC ${ }^{14}$ calculations at the B3LYP level showed that all optimized TSs were in the right reaction pathways. To obtain more accurate energies, single-point calculations on the optimized structures were performed with the larger basis set $6-311++\mathrm{G}(3 \mathrm{df}, 3 \mathrm{p})$.

The optimized structures of both no water model and one water model from the B3LYP level were reoptimized with the frozen core Møller-Plesset perturbation theory, MP2(FC)/6$31 \mathrm{G}(\mathrm{d}, \mathrm{p})$, computational level, and the single-point MP2(FC) calculations on the optimized structures were also performed with the larger basis set $6-311++\mathrm{G}(3 \mathrm{df}, 3 \mathrm{p})$. In addition, CCSD(T)/6-31G(d,p) single-point calculations have been carried out for no water-assisted model to evaluate the reliability of the barrier calculated at the B3LYP and MP2 levels.

Water solvent effects have been considered by B3LYP/6$311++\mathrm{G}(3 \mathrm{df}, 3 \mathrm{p})$ single point calculations on the optimized gasphase geometries of the two water-assisted model by using a relatively simple self-consistent reaction field $(\mathrm{SCRF})^{15}$ based on the polarizable continuum model (PCM) of the Tomasi's group. ${ }^{16}$

All reported energies are corrected by adding the unscaled Zero-Point Energy (ZPE) calculated at either the B3LYP/6-31G(d,p) or the MP2/6-31G(d,p) level.

In the five reactive steps - carbinolamine formation, dehydration, proton transfer, hydrolysis, carbinolamine eliminationGF1, GF2, and GF3 were used to represent pathways for the transamination of $\mathrm{NH}_{2} \mathrm{CH}_{2} \mathrm{COOH}+\mathrm{HCHO}+n \mathrm{H}_{2} \mathrm{O}$, where $n$ $=0,1$, and 2 .

\section{Results and Discussion}

3.1. Structure of Reactant Complex. From our calculations (B3LYP/6-31G(d,p), Figure 1), in the initial molecular complex GF1-1, N1 of glycine is located perpendicular to the formaldehyde plane at a dihedral angle formed by atoms 1, 6, 7, and 8 of $87.0^{\circ}\left(81.9^{\circ}\right)$ and at a distance from C6 of $2.539(2.702)$ $\AA$ (data in parentheses correspond to the MP2/6-31G(d,p) calculations), which means there is a weak interaction between $\mathrm{N} 1$ and C6, otherwise the formaldehyde may rotate and one of its hydrogen atoms forms a hydrogen bond with the glycine nitrogen. Although some other conformations were possible for this complex, our IRC calculations show that the carbinolamine addition starts from GF1-1, therefore just GF1-1 is discussed here.

Zwitterion formation between methylamine and formaldehyde has been reported theoretically, and the zwitterionic complex becomes more stable including more water molecules, ${ }^{6 f, 17}$ which indicates the importance of water molecules in the existence of a gas-phase zwitterionic minimum. Similar results were also
TABLE 1: Relative Energies (in $\mathrm{kcal} / \mathrm{mol}$ ) for the Stationary Points Involved in the Transamination of Glycine and Formaldehyde in Various Computational Levels ${ }^{a}$

\begin{tabular}{lrrrr}
\hline & B3LYP $^{\mathrm{a}}$ & MP2 $^{\mathrm{b}}$ & CCSD(T) $^{\mathrm{c}}$ & ${\text { CCSD }(T)^{\mathrm{d}}}^{\mathrm{c}}$ \\
\hline G+F & 0 & 0 & 0 & 0 \\
GF1-1 & 2.4 & -1.5 & -1.4 & -1.9 \\
GF1-TS1 & 28.3 & 20.9 & 25.8 & 26.0 \\
GF1-2 & -6.3 & -11.6 & -9.1 & -8.9 \\
GF1-3 & -7.5 & -13.5 & -10.5 & -10.3 \\
GF1-TS2 & 43.1 & 38.8 & 44.4 & 44.5 \\
GF1-4 & -4.3 & -7.5 & -4.6 & -4.6 \\
GF1-5 & -6.8 & -10.9 & -8.4 & -9.0 \\
GF1-TS3 & 47.9 & 45.5 & 56.0 & 55.8 \\
GF1-6 & -7.5 & -10.5 & -7.8 & -8.2 \\
GF1-7 & -10.6 & -14.1 & -12.5 & -12.8 \\
GF1-TS4 & 2.1 & -1.8 & 2.8 & 2.8 \\
GF1-8 & 1.2 & -1.3 & 2.9 & 3.0 \\
GF1-TS5 & 9.9 & 8.5 & 12.3 & 12.7 \\
GF1-9 & -8.6 & -14.8 & -13.0 & -12.7 \\
GF1-10 & -9.6 & -16.2 & -14.4 & -14.2 \\
GF1-TS6 & 8.2 & 1.1 & 6.1 & 6.3 \\
GF1-11 & -2.2 & -5.0 & -5.4 & -5.6
\end{tabular}

${ }^{a} \mathrm{G}$ and $\mathrm{F}$ represent glycine and formaldehyde, respectively. Superscripts $\mathrm{a}, \mathrm{b}, \mathrm{c}$, and $\mathrm{d}$ represent calculations at the B3LYP/6$311++\mathrm{G}(3 \mathrm{df}, 3 \mathrm{p}) / / \mathrm{B} 3 \mathrm{LYP} / 6-31 \mathrm{G}(\mathrm{d}, \mathrm{p}), \mathrm{MP} 2 / 6-311++\mathrm{G}(3 \mathrm{df}, 3 \mathrm{p}) / / \mathrm{MP} 2 /$ 6-31G(d,p), CCSD(T)/6-31G(d,p)//B3LYP/6-31G(d,p), and CCSD(T)/ 6-31G(d,p)//MP2/6-31G(d,p) levels, respectively.

found for the neutral and zwitterionic forms of glycine. ${ }^{18}$ As the carboxylic group is a good proton donor that can form strong hydrogen bonds with the electronegative group, in this study, water molecules were added to evaluate the effect of both the carboxylic group and water on stabilizing the zwitterion. When one water molecule was involved, GF2-1 (see Figure 1) is formed with the distance of C6-N1 being $0.316(0.256) \AA$ shorter than that of GF1-1 in our optimizations, which indicates a stronger interaction between these two atoms. Although the forming hydrogen bond would stabilize the complex, the energies of both complexes are slightly higher than those of isolated reactants due to the distortion of glycine in GF1-1 and GF2-1.

If two water molecules participate in this carbinolamine formation, N1 would attack C6 without any energy barrier and the distance of N1-C6 in the formed zwitterion GF3-1 (see Figure 1) would be $1.638 \AA$, indicating a stronger interaction between $\mathrm{N} 1$ and C6. The energy of the complex is $7.9 \mathrm{kcal} /$ mol lower than that of the isolated compounds, while considering the solvent effect the stabilization energy is lowered to 3.3 $\mathrm{kcal} / \mathrm{mol}$. However, without the carboxylic group the zwitterion is formed with a $2.6 \mathrm{kcal} / \mathrm{mol}$ barrier and is also $1.3 \mathrm{kcal} / \mathrm{mol}$ higher in energy than the neutral complex in the gas phase at the G2 level, of which indicates that the generation of the zwitterion is much easier in the glycine and formaldehyde model (GF model). 
TABLE 2: Relative Energies (in kcal/mol) for the Stationary Points Involved in the Water Assisted Transamination of Glycine and Formaldehyde ${ }^{a}$

\begin{tabular}{lrrlrr}
\hline & B3LYP & MP2 & & B3LYP $^{\mathrm{b}}$ & B3LYP $^{\mathrm{e}}$ \\
\hline G+F+W & 0 & 0 & G+F+W & 0 & 0 \\
GF2-1 & 0.2 & -6.7 & GF3-1 & -7.9 & -3.3 \\
GF2-TS1 & 2.0 & -4.9 & GF3-TS1 & -2.6 & -0.9 \\
GF2-2 & 3.2 & -5.9 & GF3-2 & -15.5 & -7.1 \\
GF2-TS2 & 9.4 & -0.6 & GF3-3 & -17.5 & -10.9 \\
GF2-3 & -7.4 & -17.3 & GF3-TS2 & 10.8 & 12.6 \\
GF2-4 & -11.1 & -18.9 & GF3-4 & -13.7 & -2.8 \\
GF2-TS3 & 19.2 & 14.7 & GF3-5 & -13.2 & -0.1 \\
GF2-5 & -10.0 & -15.7 & GF3-TS3 & 24.8 & 23.4 \\
GF2-6 & -8.4 & -14.5 & GF3-6 & -20.3 & -2.4 \\
GF2-TS4 & 32.8 & 29.9 & GF3-7 & -20.4 & -4.9 \\
GF2-7 & -13.7 & -19.0 & GF3-TS4 & -13.7 & -3.8 \\
GF2-8 & -14.7 & -19.5 & GF3-8 & -16.7 & -6.4 \\
GF2-TS5 & -6.8 & -11.0 & GF3-TS5 & 0.2 & 4.5 \\
GF2-9 & -8.3 & -12.1 & GF3-9 & -15.1 & -4.2 \\
GF2-TS6 & 0.9 & -2.9 & GF3-10 & -17.1 & -4.2 \\
GF2-10 & -12.5 & -20.5 & GF3-TS6 & -11.5 & -4.4 \\
GF2-11 & -12.4 & -21.8 & GF3-11 & -13.4 & -7.6 \\
GF2-TS7 & -4.7 & -14.2 & GF3-TS7 & -10.6 & -0.9 \\
GF2-12 & -5.5 & -16.0 & GF3-12 & -11.1 & 0.5 \\
GF2-TS8 & -1.2 & -11.0 & & & \\
GF2-13 & -3.7 & -12.3 & & &
\end{tabular}

${ }^{a} \mathrm{G}, \mathrm{F}$, and $\mathrm{W}$ represent glycine, formaldehyde, and water, respectively. Superscripts $a, b$, and e represent calculations at the B3LYP/ 6-311++G(3df,3p)//B3LYP/6-31G(d,p), MP2/6-311++G(3df,3p)// MP2/6-31G(d,p), and B3LYP/6-311++G(3df,3p)//B3LYP/6-31G(d,p) (PCM) levels, respectively.
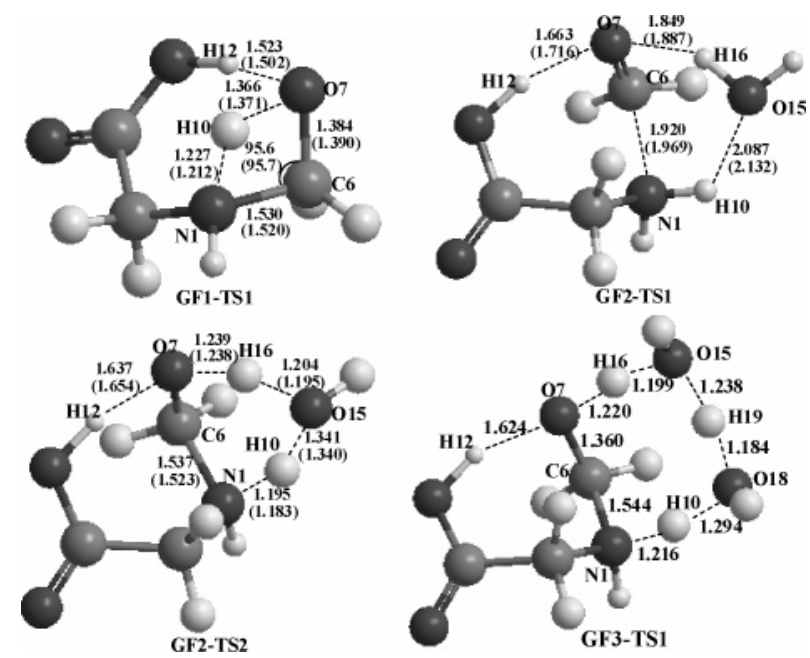

Figure 2. Optimized (B3LYP/6-31G(d,p)) geometries of the transition states for the carbinolamine formation step. The MP2/6-31G(d,p) values are in parentheses. The distances are given in angstroms while the angles are in degrees.

3.2. Carbinolamine Formation. From GF1-1, the carbinolamine GF1-2 is formed through a four-membered-ring transition state GF1-TS1 (see Figure 2) in which the H12-O7 distance is 1.523 (1.502) $\AA$, stabilizing the oxyanion. Incorporation of a single water molecule in the process of carbinolamine formation is complicated by the presence of a zwitterionic minima GF22, which has a long C6-N1 bond of 1.676 (1.614) $\AA$. The nucleophilic attack is performed via GF2-TS1 with a C6-N1 distance of 1.920 (1.969) $\AA$. From GF2-2, the carbinolamine GF2-3 can be formed if N1 is deprotonated. The proton transfer from $\mathrm{N} 1$ to $\mathrm{O} 7$ is performed through a less strained sixmembered-ring transition state represented by GF2-TS2 (see Figure 2) in which the water molecule exchanges one of its hydrogens (H16) with one of the hydrogens in the amino group
(H10). With incorporation of two water molecules, GF3-1 can produce the carbinolamine GF3-2 through GF3-TS1, which involves the concurrent transfer of three protons within the eightmembered ring. The structures of GF1-2, GF2-2, GF2-3, GF31 , and GF3-2 can be seen in the Supporting Information.

The schematic potential energy surface for the carbinolamine formation is given in Figure 3, revealing the catalytic effect of water molecules. Relative to the reactant complexes, the barrier decreases from $25.9 \mathrm{kcal} / \mathrm{mol}$, to $9.6 \mathrm{kcal} / \mathrm{mol}$, and to $5.3 \mathrm{kcal} /$ mol with the inclusion of more water molecules at the B3LYP level. The barriers calculated at the MP2 level are about $3 \mathrm{kcal} /$ mol lower than those at the B3LYP level for $n=0$ and 1 ( $n$ representing the number of water molecules). Furthermore, $\operatorname{CCSD}(\mathrm{T})$ calculations show that the barriers at both the B3LYP and the MP2 level are several $\mathrm{kcal} / \mathrm{mol}$ lower but still reliable. The solvent effect lowers the proton-transfer barrier in GF3TS1 by $2.8 \mathrm{kcal} / \mathrm{mol}$ (data with superscript "e" in Figure 3). The barriers in the GF model are lower than those in the methylamine-formaldehyde model $^{6 f}$ (MF model for short) because the carboxylic group can effectively stabilize the TSs through forming a strong hydrogen bond especially without water molecules.

3.3. Dehydration. In the absence of water molecules, the formation of imine can proceed via a four-membered-ring transition state GF1-TS2 (see Figure 4) in which the N-hydrogen of GF1-3 is transferred to the hydroxyl oxygen, resulting in the elimination of a single water molecule. At the $\operatorname{CCSD}(\mathrm{T})$ level, GF1-TS2 lies 54.9 (54.8) kcal/mol above GF1-3, while the imine intermediate GF1-4 lies 5.9 (5.7) $\mathrm{kcal} / \mathrm{mol}$ above GF1-3. The structures of GF1-3 and GF1-4 can be seen in the Supporting Information.

Inclusion of a single water molecule produces a less strained transition state GF2-TS3 (see Figure 4), and the barrier decreases to 30.3 (33.6) $\mathrm{kcal} / \mathrm{mol}$, which predicts that water is effective in lowing the proton-transfer barrier. However, the barrier decreases by just $2.0 \mathrm{kcal} / \mathrm{mol}$ when including one more water molecule. Furthermore, with incorporation of the solvation energy terms the dehydration barrier decreases from $28.3 \mathrm{kcal} /$ mol to $23.5 \mathrm{kcal} / \mathrm{mol}$ due to the highly polarized nature of TS. From Figure 4, we can see that as the number of $\mathrm{H}_{2} \mathrm{O}$ increases, the distance of $\mathrm{C} 6-\mathrm{N} 1$ and $\mathrm{H} 11-\mathrm{N} 1$ decreases while the angle of $\mathrm{H} 11-\mathrm{N} 1-\mathrm{C} 6$ and $\mathrm{O} 7-\mathrm{C} 6-\mathrm{N} 1$ increases. As the carboxylic group is far away from the reactive center and just forms a weak hydrogen bond with the imine nitrogen, the barriers are almost the same as those in the MF model. ${ }^{6 f}$ The schematic potential energy surface is shown in Figure 3a.

3.4. 1,3 Proton Transfer. The dehydration is followed by the tautomeric conversion of imine 1 to imine 2 . When $\mathrm{H} 8$ and H9 (see GF1-TS3 in Figure 5) is replaced by some other functional groups, the proton transfer would produce a chiral center C6; however, in nonenzymatic transamination both $\mathrm{R}$ and $\mathrm{S}$ configurations are formed without stereoselectivity. In the proton-transfer step, GF1-4 first transforms to GF1-5 in which $\mathrm{H}_{2} \mathrm{O}$ forms a hydrogen bond with $\mathrm{H} 14$. In the transition state GF1-TS3 (see Figure 5), a twisted six-membered ring is formed, the structure of which corresponds to a situation in which the proton from $\mathrm{CH}_{2}$ is being transferred to the water molecule, which, in turn, has already started to transfer proton to $\mathrm{C} 6$ in a concerted way. At the CCSD(T) level, GF1-TS3 lies $64.4(64.8) \mathrm{kcal} / \mathrm{mol}$ above GF1-5. The completion of this step leads to a new imine GF1-6 with a water molecule coordinated to $\mathrm{H} 10$.

The addition of a single water molecule assists proton transfer through forming a less strained eight-membered-ring transition 

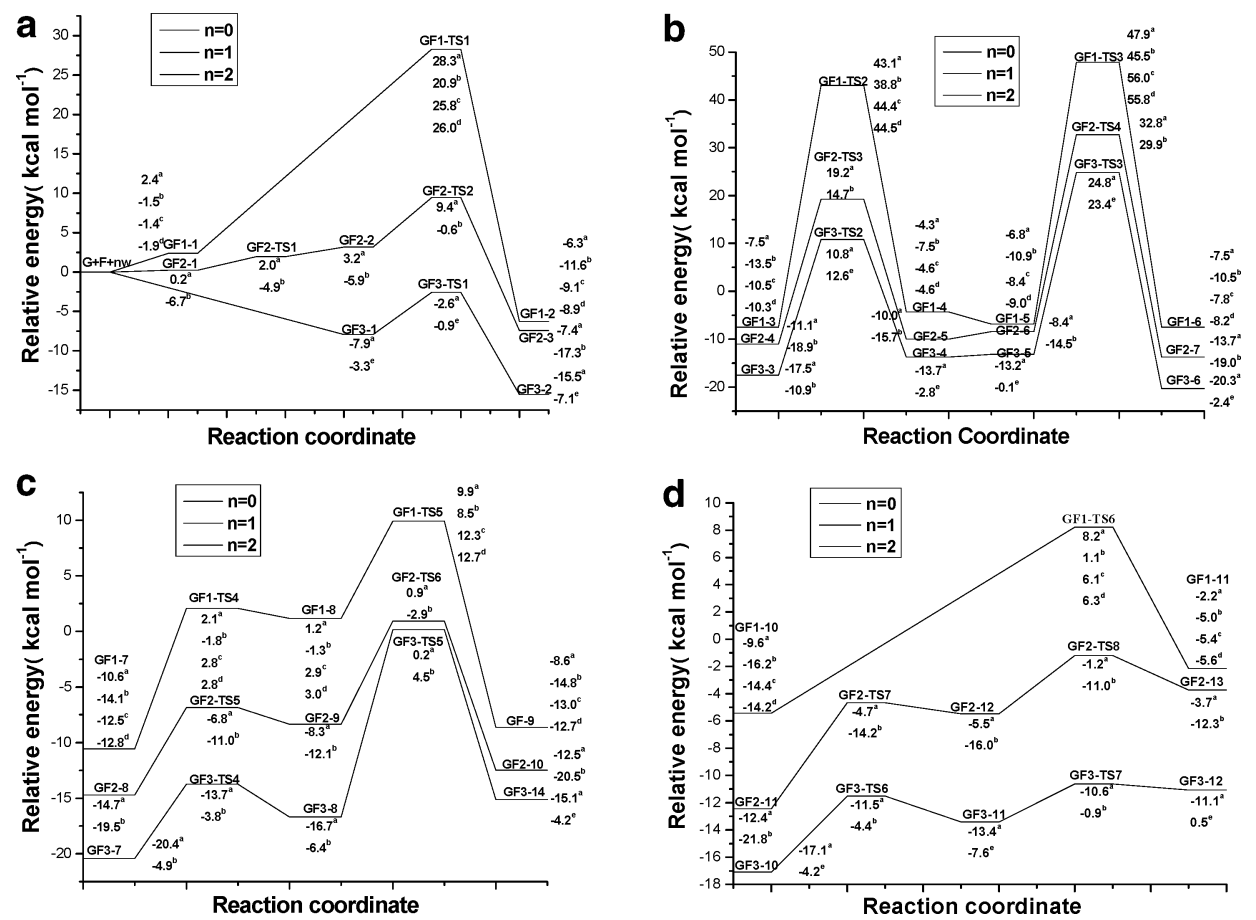

Figure 3. Reaction profiles obtained from various levels to study the carbinolamine formation (a), dehydration, 1,3 proton transfer (b), hydrolysis (c), and carbinolamine elimination (d) involved in the transamination of $\mathrm{NH}_{2} \mathrm{CH}_{2} \mathrm{COOH}+\mathrm{HCHO}+n \mathrm{H}_{2} \mathrm{O}$, where $n=0$, 1,2 . The superscripts $\mathrm{a}, \mathrm{b}, \mathrm{c}, \mathrm{d}$, and e in the data represent calculations at B3LYP/6-311++G(3df,3p)//B3LYP/6-31G(d,p), MP2/6-311++G(3df,3p)//MP2/6-31G(d,p), $\operatorname{CCSD}(\mathrm{T}) / 6-31 \mathrm{G}(\mathrm{d}, \mathrm{p}) / / \mathrm{B} 3 \mathrm{LYP} / 6-31 \mathrm{G}(\mathrm{d}, \mathrm{p}), \operatorname{CCSD}(\mathrm{T}) / 6-31 \mathrm{G}(\mathrm{d}, \mathrm{p}) / / \mathrm{MP} 2 / 6-31 \mathrm{G}(\mathrm{d}, \mathrm{p})$, and B3LYP/6-311++G(3df,3p)//B3LYP/6-31G(d,p) (PCM) levels, respectively.

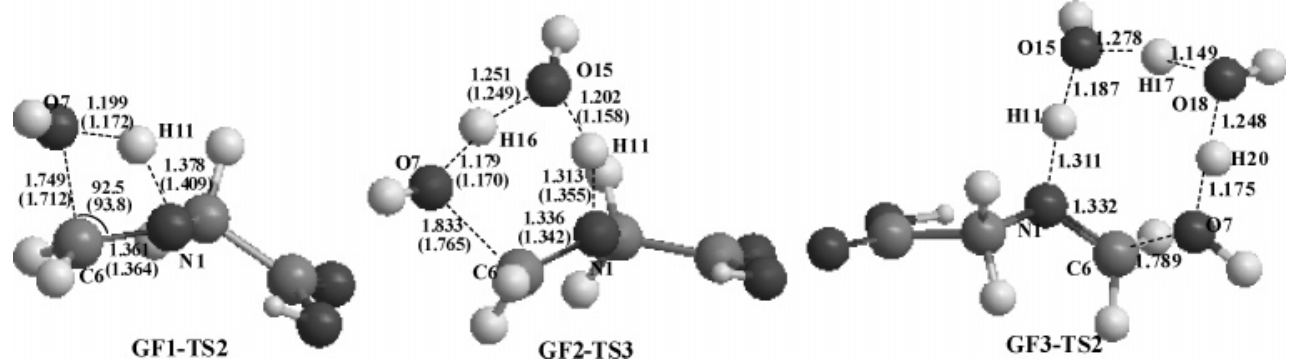

Figure 4. Optimized (B3LYP/6-31G(d,p)) geometries of the transition states for the dehydration step. The MP2/6-31G(d,p) values are in parentheses. The distances are given in angstroms while the angles are in degrees.
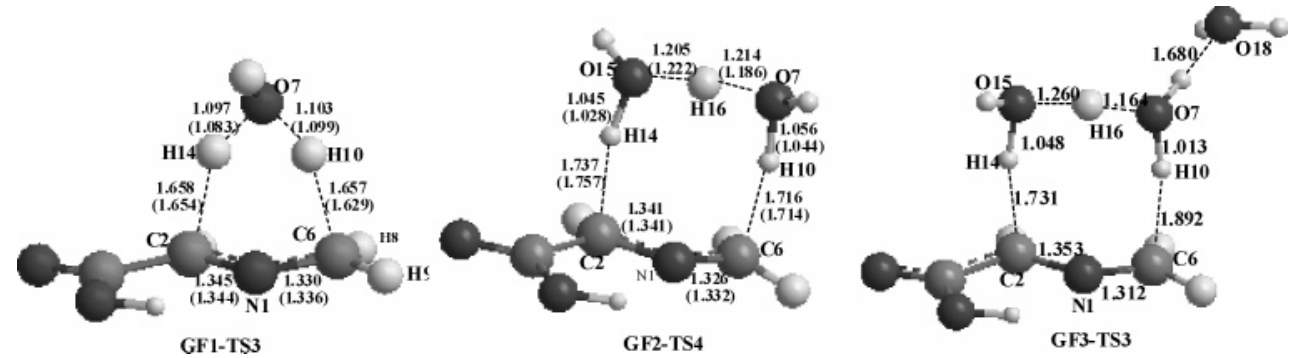

Figure 5. Optimized (B3LYP/6-31G(d,p)) geometries of the transition states for the hydrogen transfer step. The MP2/6-31G(d,p) values are in parentheses. The distances are given in angstroms while the angles are in degrees.

state GF2-TS4 (see Figure 5), and the barrier decreases to 41.2 (44.4) $\mathrm{kcal} / \mathrm{mol}$. However, incorporation of one more water molecule has little effect on lowing the barrier as this water molecule stabilizes both the starting intermediate and transition state at the same extent. Compared to the stabilization energy on the isolated reactant, the water solvent destabilizes GF3-5 by $13.1 \mathrm{kcal} / \mathrm{mol}$ but stabilizes $\mathrm{GF} 3-\mathrm{TS} 3$ by $0.6 \mathrm{kcal} / \mathrm{mol}$, therefore, imine isomerization via GF3-TS3 requires $23.5 \mathrm{kcal} /$ mol. A schematic energy profile for imine isomerization is presented in Figure 3b. The structures of GF1-5 and GF3-5 can be seen in the Supporting Information.
3.5. Hydrolysis. The transamination is symmetric to some extent; however, due to the participation of the adjacent carboxylic group, the mechanism of hydrolysis is much different from that of dehydration and general imine hydrolysis. In our calculations, the first step is the proton transferring from the carboxylic group to the imine nitrogen with the formation of zwitterion, and the second step is the water molecule attacking the imine carbon, simultaneously one of its hydrogen atoms transferring to the carboxylic oxygen anion.

The proton transfer causes $\mathrm{C} 2$ in GF1-7 to become more eletronphilic. Then $\mathrm{O} 7$ attacks $\mathrm{C} 2$ with $\mathrm{H} 14$ transferring to $\mathrm{O} 5$ 

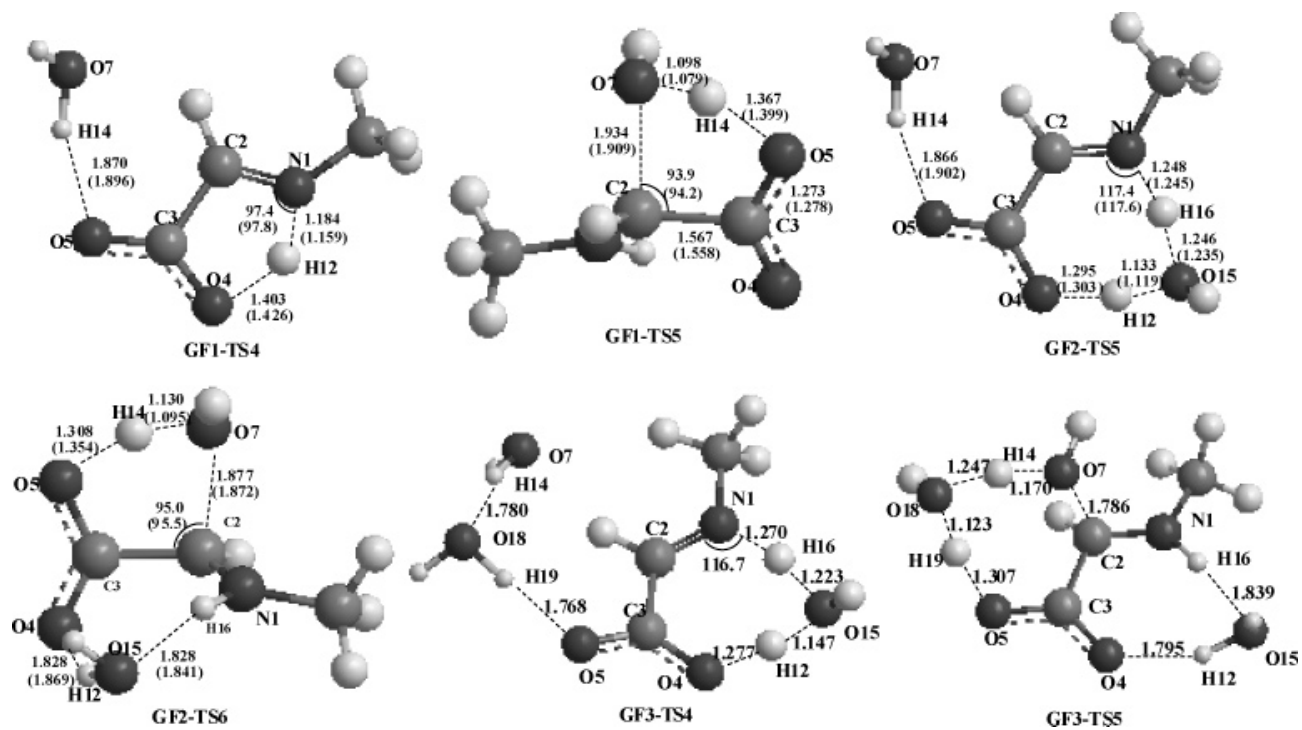

Figure 6. Optimized (B3LYP/6-31G(d,p)) geometries of the transition states for the hydrolysis step. The MP2/6-31G(d,p) values are in parentheses. The distances are given in angstroms while the angles are in degrees.
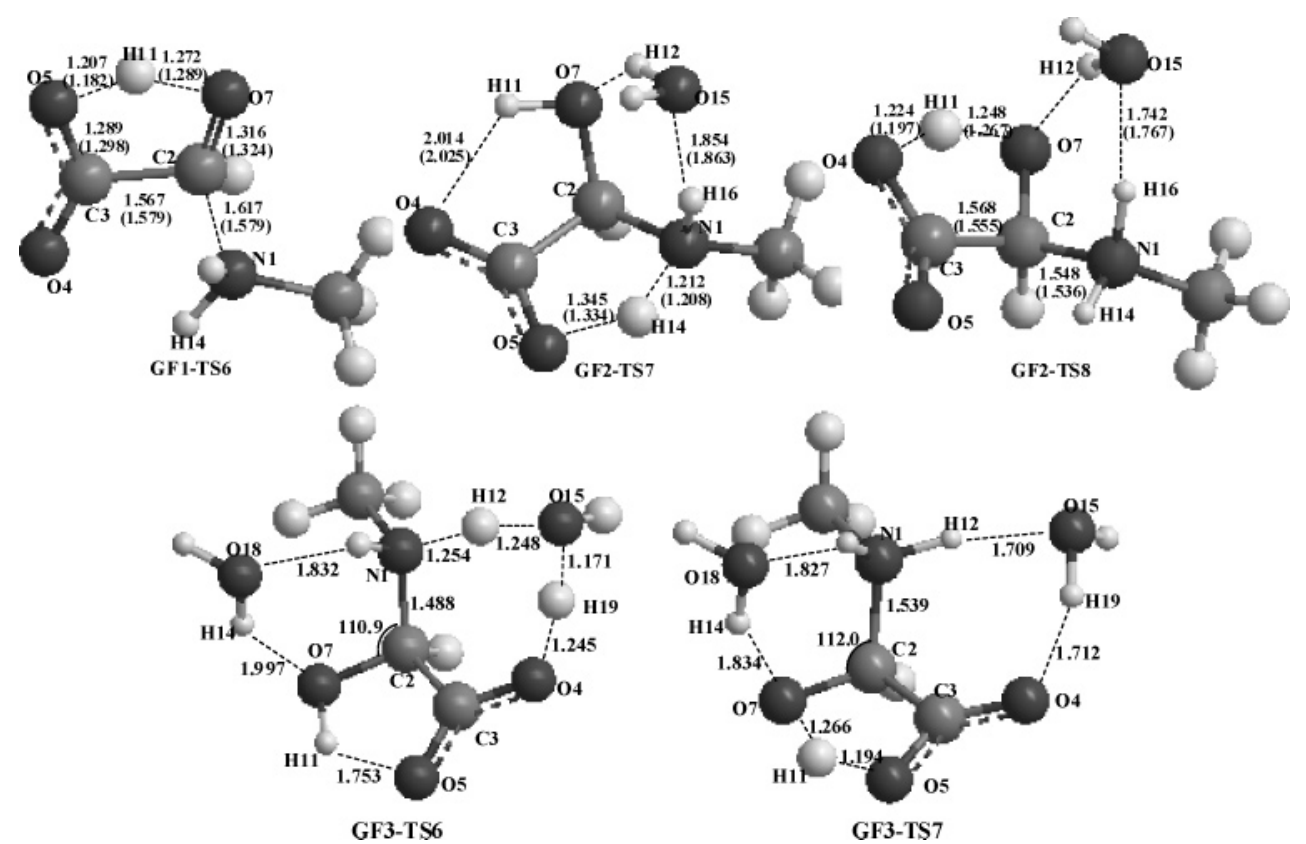

Figure 7. Optimized (B3LYP/6-31G(d,p)) geometries of the transition states for the carbinolamine elimilation step. The MP2/6-31G(d,p) values are in parentheses. The distances are given in angstroms while the angles are in degrees.

and forms a five-membered transition state GF1-TS5 (see Figure 6) with less tension than GF1-TS2 in a concerted mechanism. Therefore, GF1-TS2 lies 32.1 (31.8) kcal/mol below GF1-TS2 at the $\operatorname{CCSD}(\mathrm{T})$ level. The second water molecule involved can serve as an effective proton-transfer carrier to lower the barrier of zwitterion formation by 4.8 (3.8) $\mathrm{kcal} / \mathrm{mol}$. Incorporation of one more water molecule causes the formation of the new carbinolamine through a twisted seven-membered ring transition state GF3-TS5. However, the barrier relative to the zwitterion increases from $9.3 \mathrm{kcal} / \mathrm{mol}$ to $16.8 \mathrm{kcal} / \mathrm{mol}$ due to the distortion of TS. By including the solvent effect the hydrolysis barrier relative to GF3-7 decreases from $20.2 \mathrm{kcal} / \mathrm{mol}$ to $9.4 \mathrm{kcal} /$ mol. Compared to direct hydrolysis, the barrier is much lower when the carboxylic group is directly involved in the reaction, the reason for which is that zwitterionic intermediates are formed with more reactivity. Presented in Figure $3 \mathrm{c}$ is a schematic energy profile for imine hydrolysis from $\mathrm{CH}_{3} \mathrm{~N}=\mathrm{CHCOOH}$ with zero, one, and two water molecules. The structures of GF1-7 and GF3-7 can be seen in the Supporting Information.

3.6. Carbinolamine Elimination. The elimination results in the formation of glyoxylic acid and methylamine. Our calculations show that the mechanism is totally different from that of carbinolamine formation due to incorporation of the adjacent carboxylic group. The elimination can proceed via GF1-TS6 (see Figure 7) in which $\mathrm{H} 14$ transfers from $\mathrm{O} 4$ to $\mathrm{N} 1$ and $\mathrm{H} 11$ transfers from $\mathrm{O} 7$ to $\mathrm{O} 5$. IRC calculation confirms that GF1TS6 links the carbinolamine GF1-10 and the product complex GF1-11. GF1-TS6 lies 19.7 (19.7) kcal/mol below GF1-TS1 at the $\operatorname{CCSD}(\mathrm{T})$ level.

The addition of water molecules results in stepwise pathways. When a single water molecule is involved, it is double-bridged to $\mathrm{H} 16$ and $\mathrm{O} 7$, and due to this hydrogen bond network, the transfer of $\mathrm{H} 14$ from $\mathrm{O} 5$ to $\mathrm{N} 1$ forms a stable zwitterionic intermediate GF2-12 in which N1 is the positive center and the 


\section{SCHEME 2}

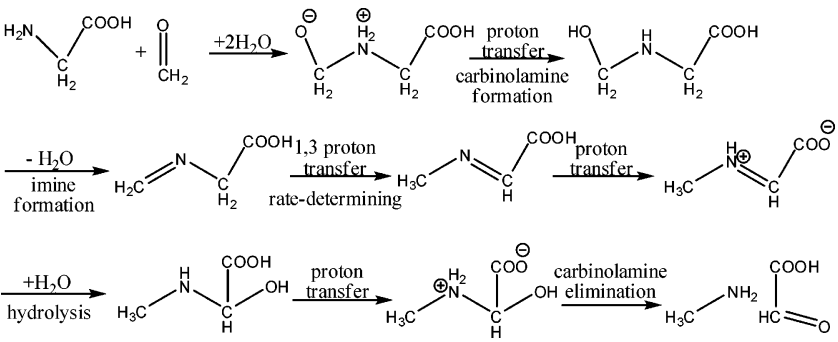

carboxylic anion is the negative center. The transition state GF2TS8 connecting GF2-12 and GF2-13 lies 11.2 (10.8) kcal/mol above GF2-11 with the C2-N1 distance of 1.548 (1.536) $\AA$. When another water molecule is involved, it assists the proton transfer with the formation of zwitterion GF3-11, which is 3.4 $\mathrm{kcal} / \mathrm{mol}$ lower than that for GF3-10 in water solvent. The formation of product complex GF3-12 is accomplished through GF3-TS7, with a barrier of $6.7 \mathrm{kcal} / \mathrm{mol}$ in water solvent. A schematic energy profile for carbinolamine elimination from $\mathrm{CH}_{3} \mathrm{NHCH}(\mathrm{OH}) \mathrm{COOH}$ complexed with zero, one, and two water molecules is presented in Figure 3d, from which it can be predicted that in aqueous solution the carbinolamine formation between an amino acid and an $\alpha$-keto acid may be barrierless. The structures of GF1-11, GF2-11, GF2-12, GF310, GF3-11, and GF3-12 can be seen in the Supporting Information.

\section{Conclusions}

A theoretical examination of the water-assisted transamination between glycine and formaldehyde was given in this paper, the complete mechanism of which was summarized in Scheme 2. The results indicate that the proton-transfer step is the ratelimiting one while the other four steps are relatively easier and the influence of water is beyond its role as a solvent. The water molecules take part in the reaction by performing proton transfer and stabilizing the zwitterion. Due to the participation of these water molecules, some concerted steps become stepwise. Thus, water contribution to the transamination reaction is not restricted only to solvent effects, but it also acts as a reactive species. In addition, it was found that water solvent stabilizes TSs much more than intermediates which results in a barrier decrease from gas phase to water medium. Furthermore, the carboxylic group causes the hydrolysis and elimination through a general acidcatalyzed mechanism. Anyway, at room temperature, the transamination cannot occur and just imine is formed according to our calculations, which is in good agreement with experimental results.

Here the reference reaction of enzymatic transamiantion is presented due to the complexity of enzymatic transamination; however, it provides some useful information in finding the origin of the catalytic efficiency of transaminase. Further work is needed to study how the enzyme determines the chirality of newly formed amino acid.

Acknowledgment. This work was supported by a grant from the National Natural Science Foundation of China (grant no. 20573011) and Major State Basic Research Development Programs (grant nos. 2004CB719903 and 2002CB613406).

Supporting Information Available: Structures for all stationary points reported in the present work. This material is available free of charge via the Internet at http://pubs.acs.org.

\section{References and Notes}

(1) (a) Walsh, C. In Enzymatic Reaction Mechanisms; Freeman: San Francisco, CA, 1979; pp 777-827. (b) Christen, P.; Metzler, D. E.
Transaminases; Wiley: New York, 1985. (c) Martell, A. E. Acc. Chem. Res. 1989, 22, 115-124.

(2) (a) Green, D. E.; Leloir, L. F.; Nocito, V. J. Biol. Chem. 1945 161, 559-582. (b) Ayling, A. E.; Dunathan, H. C.; Snell, E. E. Biochemistry 1968, 7, 4537-4542. (c) Dunathan, H. C.; Voet, J. G. Proc. Natl. Acad. Sci. U.S.A. 1974, 71, 3888-3891. (d) Tobler, H. P.; Christen, P.; Gehring, H. J. Biol. Chem. 1986, 261, 7105-7108. (e) Gehring, H. Biochemistry 1984, 23, 6335-6340. (f) Nishimura, K.; Ito, J.; Yoshimura, T.; Esakik, N.; Soda, K. Bioorg. Med. Chem. 1994, 2, 605-607. (g) Cameron, M.; Cohen, D.; Cottrell, I. F.; Kennedy, D. J.; Roberge, C.; Chartrain, M. J. Mol. Catal. B Enzym. 2001, 14, 1-5. (h) Soda, K.; Yoshimura, T.; Esaki, N. Chem. Rec. 2001, 1, 373.

(3) (a) Herbst, R. M.; Engel, L. L. J. Biol. Chem. 1934, 107, 505512. (b) Herbst, R. M. J. Am. Chem. Soc. 1936, 58, 2239-2243. (c) Brewer S.; Herbst, R. M. J. Org. Chem. 1941, 6, 867-877. (d) Herbst, R. M.; Rittenberg, D. J. Org. Chem. 1943, 8, 380-389. (e) Harvill, E. K.; Herbst, R. M. J. Org. Chem. 1944, 9, 21-30. (f) Nakada, H. I.; Weinhouse, S. J. Biol. Chem. 1953, 204, 831-836.

(4) (a) Banks, B. E. C.; Dianantis, A. A.; Vernon, C. A. J. Chem. Soc 1961, 4235. (b) Toney, M. D.; Kirsch, J. F. Biochemistry 1993, 32, 14711479. (c) Pishchugin, F. V.; Tuleberdiev, I. T. Russ. J. Gen. Chem. 2005, 75,1538 .

(5) (a) Soloshonok, V. A.; Ono, T. Tetrahedron 1996, 52, 1470114712. (b) Soloshonok, V. A.; Kukhar, V. P. Tetrahedron 1996, 52, $6953-$ 6964. (c) Soloshonok, V. A.; Kukhar, V. P. Tetrahedron 1996, 52, 83078314.

(6) (a) Shokhen, M. A.; Tikhomirov, D. A.; Yeremetev, A. V Tetrahedron 1983, 39, 2975-2979. (b) Williams, I. H.; Spangler, D.; Femec, D. A.; Maggiora, G. M.; Schowen, R. L. J. Am. Chem. Soc. 1983, 105, 31-40. (c) Williams, I. H.; Spangler, D.; Maggoria, G. M.; Schowen, R. L. J. Am. Chem. Soc. 1985, 107, 7717-7723. (d) Williams, I. H. J. Am. Chem. Soc. 1987, 109, 6299-6307. (e) Ospina, E.; Villaveces, J. L. J. Mol. Struct. (THEOCHEM) 1993, 287, 201-209. (f) Hall, N. E.; Smith, B. J. J Phys. Chem. A 1998, 102, 4930-4938. (g) Yang, W.; Drueckhammer, D. G. J. Am. Chem. Soc. 2001, 123, 11004-11009. (h) Ilieva, S.; Galabov, B.; Musaev, D. G.; Morokuma, K.; Schaefer, H. F., III J. Org. Chem. 2003, 68, 1496-1502. (i) Mascavage, L. M.; Sonnet, P. E.; Dalton, D. R. J. Org. Chem. 2006, 71, 3435-3443. (j) Courmier, D.; Gardebien, F.; Minot, C.; St-Amant, A. J. Mol. Struct. (THEOCHEM) 2005, 405, 357-363.

(7) Yamafaka, H.; Nagase, S.; Ando, T.; Hanafusala, T. J. Am. Chem Soc. 1986, 108, 601-606.

(8) Feldmann, M. T.; Widicus, S. L.; Blake, G. A.; Kent, d. R., IV; Goddard, D. A., III J. Chem. Phys. 2005, 123, 9606-9610.

(9) (a) Salvà, A.; Donoso, J.; Frau, J.; Muñoz, F. J. Mol. Struct. (THEOCHEM) 2002, 577, 229-238. (b) Salvà, A.; Donoso, J.; Frau, J.; Muñoz, F. J. Phys. Chem. A 2003, 107, 9409-9414.

(10) (a) Brault, M.; Pollack, R. M.; Bevins, C. L. J. Org. Chem. 1976, 41, 346-350. (b) Hine, J.; Via, F. A.; Gotkis, J. K.; Craig, J. C. J. Am. Chem. Soc. 1970, 92, 5186-5193. (c) Sayer, J. M.; Jencks, W. P. J. Am. Chem. Soc. 1973, 95, 5637-5649. (d) Sayer, J. M.; Pinsky, B.; Schonbrunn, A.; Washtien, W. J. Am. Chem. Soc. 1974, 96, 7998-8009. (e) Sayer, J. M.; Jenks, W. P. J. Am. Chem. Soc. 1977, 99, 464-474. (f) Sayer, J. M.; Conlin, P. J. Am. Chem. Soc. 1980, 102, 3592-3600.

(11) For example: (a) Antonczak, S.; Ruiz-LEpez, M. F. J.; Rivail, L. J. Am. Chem. Soc. 1994, 116, 3912-3921. (b) Bell, R. L.; Taveras, D. L.; Truong, T. N; Simons, J. Int. J. Quantum Chem. 1997, 63, 861-874. (c) Kallies, B.; Mitzner, R. J. Mol. Model. 1998, 4, 183-196. (d) Gardebien, F.; Sevin, A. J. Phys. Chem. A 2003, 107, 3925-3934. (e) Zahn, D. Eur J. Org. Chem. 2004, 4020-4023. (f) Kwok, W. M.; Zhao, C.; Li, Y.-L.; Guan, X.; Wang, D.; Phillips, D. L. J. Am. Chem. Soc. 2004, 126, 31193131. (g) Gorb, L.; Asensio, A.; Tuñón, I.; Ruiz-lópez, M. F. Chem. Eur. J. 2005, 11, 6743-6753. (h) Zhao, C.; Lin, X.; Kwok, W. M.; Guan, X.; Du, Y.; Wang, D.; Hung, K. F.; Phillips, D. L. Chem. Eur. J. 2005, 11, 1093-1108. (i) Li, Q.-S.; Fang, W.-H.; Yu, J.-G. J. Phys. Chem. A 2005, 109, 3983-3990.

(12) Frisch, M. J.; Trucks, G. W.; Schlegel, H. B.; Scuseria, G. E.; Robb M. A.; Cheeseman, J. R.; Montgomery, J. A., Jr.; Vreven, T.; Kudin, K. N.; Burant, J. C.; Millam, J. M.; Iyengar, S. S.; Tomasi, J.; Barone, V.; Mennucci, B.; Cossi, M.; Scalmani, G.; Rega, N.; Petersson, G. A.; Nakatsuji, H.; Hada, M.; Ehara, M.; Toyota, K.; Fukuda, R.; Hasegawa, J.; Ishida, M.; Nakajima, T.; Honda, Y.; Kitao, O.; Nakai, H.; Klene, M.; Li, X.; Knox, J. E.; Hratchian, H. P.; Cross, J. B.; Adamo, C.; Jaramillo, J.; Gomperts, R.; Stratmann, R. E.; Yazyev, O.; Austin, A. J.; Cammi, R.; Pomelli, C.; Ochterski, J. W.; Ayala, P. Y.; Morokuma, K.; Voth, G. A.; Salvador, P.; Dannenberg, J. J.; Zakrzewski, V. G.; Dapprich, S.; Daniels, A. D.; Strain, M. C.; Farkas, O.; Malick, D. K.; Rabuck, A. D.; Raghavachari, K.; Foresman, J. B.; Ortiz, J. V.; Cui, Q.; Baboul, A. G.; Clifford, S.; Cioslowski, J.; Stefanov, B. B.; Liu, G.; Liashenko, A.; Piskorz, P.; Komaromi, I.; Martin, R. L.; Fox, D. J.; Keith, T.; Al-Laham, M. A.; Peng, C. Y.; Nanayakkara, A.; Challacombe, M.; Gill, P. M. W.; Johnson, 
B.; Chen, W.; Wong, M. W.; Gonzalez, C.; Pople, J. A. Gaussian03, Revision B.02; Gaussian Inc.: Pittsburgh, PA, 2003.

(13) (a) Becke, A. D. J. Chem. Phys. 1993, 98, 5648-5652. (b) Lee, C.; Yang, W.; Parr, R. G. Phys. Rev. B 1988, 37, 785-789.

(14) (a) Gonzalez, C.; Schlegel, H. B. J. Chem. Phys. 1989, 90, 21542161. (b) Gonzalez, C.; Schlegel, H. B. J. Phys. Chem. 1990, 94, 55235527.

(15) Tomasi, J.; Persico, M. Chem. Rev. 1994, 94, 2027-2094.
(16) (a) Cances, E.; Mennucci, B.; Tomasi, J. J. Chem. Phys. 1997, 107, 3032-3041. (b) Cossi, M.; Barone, V.; Cammi, R.; Tomasi, J. Chem. Phys. Lett. 1996, 255, 327-335. (c) Barone, V.; Cossi, M.; Tomasi, J. J. Comput. Chem. 1998, 19, 404-417.

(17) Hall, N. E.; Smith, B. J. J. Phys. Chem A 1998, 102, 3985-3990.

(18) (a) Jensen, J. H.; Gordon, M. S J. Am. Chem. Soc. 1995, 117, 81598170. (b) Tortonda, F. R.; Pascual-Ahuir, J. L.; Silla, E.; Tuñón, I. Chem. Phys. Lett. 1996, 260, 21-26. 